\title{
The Efficiency of Microencapsulation with Alginate, Gelatin, and Chitosan on the Survival of Bacillus subtilis
}

\author{
Umaporn Khimmakthong ${ }^{1,2^{*}}$, Prasit Khumpouk ${ }^{1}$, \\ Napatsakorn Saichanaphan ${ }^{1}$, Yotaka Intarasin ${ }^{1}$, and \\ Krittapas Tirawanichakul ${ }^{1}$
}

\begin{abstract}
${ }^{1}$ Faculty of Veterinary Science, Rajamangala University of Technology Srivijaya, Thungyai Sub-district, Thungyai District, Nakhon Si Thammarat, 80240, Thailand

${ }^{2}$ Animal Infectious Diseases in South of Thailand Research Unit, Faculty Veterinary Science, Rajamangala University of Technology Srivijaya, Nakorn Si Thammarat, 80240, Thailand
\end{abstract}

Corresponding author.E-mail: tal_biot@hotmail.com https://doi.org/10.12982/CMUJNS.2020.0044

Received: August 29, 2019 Revised: November 19, 2019 Accepted: December 6, 2019

\begin{abstract}
In this research, the method that helps Bacillus subtilis to survive in high temperatures and low $\mathrm{pH}$ was examined. B. subtilis were encapsulated with alginate $(A)$, alginate together with gelatin $(A G)$, alginate together with chitosan (AC), and alginate together with gelatin and chitosan (AGC). Then the gel bead sizes and the release of bacteria from the gel beads were measured. The gel beads using $18 G$ needle has the highest amount of $B$. subtilis release and was found that $A C$ and $A G C$ encapsulation had the highest efficiency of the release of $B$. subtilis. The survival of $B$. subtilis at high temperature (60 and $90{ }^{\circ} \mathrm{C}$ ) and at low $\mathrm{pH}$ ( $\mathrm{pH} 4$ and 2) was evaluated. At high temperature, the percentage survival of $B$. subtilis encapsulated with $A C$ increases when compared to non-encapsulated $B$. subtilis $(B S)$ and $A G C$ as statistically significant $(P<0.05)$. At low $\mathrm{pH}$, the percentage survival of $B$. subtilis encapsulated with $A C$ and $A G C$ increased as statistically significant compared to $B S(P<0.05)$. The average percentage survival of $A C$ at $\mathrm{pH} 4$ and 2 are $\mathbf{9 8 . 0 3 \%}$ and $45.15 \%$, respectively. The average percentage survival of $A G C$ at pH 4 and 2 are $90.90 \%$ and $51.02 \%$, respectively.
\end{abstract}

Keywords: Alginate, Bacillus subtilis, Chitosan, Gelatin, Microencapsulation 


\section{INTRODUCTION}

Probiotics are living bacteria. If the animals receive the right amount, they will benefit the health of the host cell. They will help balance the intestinal microflora appropriately, resulting in good growth of animals and prevention of pathogens replication (Kesarcodi-Watson et al., 2008). Good probiotics must not be pathogenic microorganisms, no resistance gene and most importantly, have to withstand in high temperatures that may be encountered in industrial production processes, resistant to high acidity in the stomach and can tolerate in salt bile from the host's small intestine. There are many reports of probiotics used in animals, especially in aquatic animals (Park et al., 2016; Standen et al., 2016; Makled et al., 2017). Bacillus spp. is considered as one of the most evaluated bacteria in fish. These bacteria are common in nature, including soil, water, and air, capable of producing endospore for unfavorable environments. And be confident that it is a stable probiotic when used as an animal food additive (Hong et al., 2005). B. subtilis is a species that has been commonly reported as a potential probiotic with the ability to produce many types of antimicrobials. In addition, B. subtilis is generally considered to be safe in animals and humans (AlGburi et al., 2016).

The problem that occurs when using probiotics in animals is probiotics cell are often destroyed by gastric juices of animals with high acidity. In addition, bile salts that are secreted from the small intestine have the ability to destroy microorganisms, causing the number of probiotics that the animals have received reduced and not enough to function. Microencapsulation is a technology that has been developed and used in nutrition for aquaculture to increase the potential of using probiotics in the gastrointestinal tract. The probiotic particles are coated or trapped inside the capsule material ranging in size from less than one micron to hundreds of microns (Bansode et al., 2010). Alginate, gelatin, and chitosan are the materials that are used to coat probiotics cell and are reported to be effective in preventing bacterial probiotics from various critical conditions (Trabelsi et al., 2014; Gandomi et al., 2016; Wu and Zhang, 2018).

\section{MATERIALS AND METHODS}

\section{Materials}

B. subtilis were purchased from Thailand Institute of Scientific and Technological Research (TISTR), Thailand (TISTR 2057). The main materials used in the experiment are nutrient agar (NA) (Himedia, India), nutrient broth (NB) (Himedia, India), alginic acid sodium salt from brown algae (Sigma, Norway), gelatine (Merck, Switzerland), chitosan (Aldrich, Iceland), $\mathrm{CaCl}_{2}$ (Merck, Germany), $\mathrm{NaCl}$ (Merck, Denmark), and glycerol 99.5\% (ANaPURE, Hong Kong). 


\section{B. subtilis culture}

B. subtilis were cultured in NA at $37^{\circ} \mathrm{C}$ for 16 hours. After that, a single colony bacterium was introduced into $\mathrm{NB}$, incubated in a $180 \mathrm{rpm}$ shaking machine at $37^{\circ} \mathrm{C}$ for 16 hours. After that, the bacteria were spun at $5,000 \mathrm{rpm}$ for 15 minutes, removed the media, and washed the cells 3 times by $10 \mathrm{~mL}$ of $0.85 \%$ $\mathrm{NaCl}(\mathrm{w} / \mathrm{v})$. Dissolved the cells in $0.85 \% \mathrm{NaCl}(\mathrm{w} / \mathrm{v})+0.1 \%$ glycerol and adjusted the cells concentration to $10^{9}$ cells $/ \mathrm{mL}$ (adjusted O.D. value at $550 \mathrm{~nm}$ to 1 )

\section{Encapsulation of $B$. subtilis with alginate, gelatin and chitosan}

Encapsulation of B. subtilis with alginate (A). B. subtilis that adjusted to $10^{9}$ cells $/ \mathrm{mL}$ were encapsulated with sodium alginate in accordance with Pinpimai et al. (2015) method. $10 \mathrm{~mL}$ of $B$. subtilis cells are mixed together with $40 \mathrm{~mL}$ of aseptic $2 \%(\mathrm{w} / \mathrm{v})$ sodium alginate, $\mathrm{pH} 6.9$, then sodium alginate matrix were dropped into sterile $0.1 \mathrm{M} \mathrm{CaCl}_{2}$ using $18 \mathrm{G}$ syringes, the height of the syringe tip and $\mathrm{CaCl}_{2}$ solution equal to $5 \mathrm{~cm}$, incubated the gel beads in $0.1 \mathrm{M}$ $\mathrm{CaCl}_{2}$ for 30 minutes to increase gel strength. Then separate the gel beads by filtered through filter paper No. 4 , washed the gel beads 2 times with $0.85 \% \mathrm{NaCl}$ $(\mathrm{w} / \mathrm{v})$.

Encapsulation of B. subtilis with alginate together with gelatin (AG). $B$. subtilis that adjusted to $10^{9}$ cells $/ \mathrm{mL}$ were encapsulated with sodium-alginate and gelatin in accordance with Mathews (2017) method. $10 \mathrm{~mL}$ of B. subtilis cells are mixed together with $40 \mathrm{~mL}$ of aseptic $2 \%(\mathrm{w} / \mathrm{v})$ sodium alginate $+2 \%(\mathrm{w} / \mathrm{v})$ gelatin, $\mathrm{pH} 6.9$, then sodium-alginate matrix were dropped into sterile $0.1 \mathrm{M}$ $\mathrm{CaCl}_{2}$ using $18 \mathrm{G}$ syringes, the height of the syringe tip and $\mathrm{CaCl}_{2}$ solution equal to $5 \mathrm{~cm}$, incubated the gel beads in $0.1 \mathrm{M} \mathrm{CaCl}_{2}$ for 30 minutes to increase gel strength. Then, separated the gel beads by filtered through filter paper No. 4, washed the gel beads 2 times with $0.85 \% \mathrm{NaCl}(\mathrm{w} / \mathrm{v})$.

Encapsulation of $B$. subtilis with alginate and chitosan (AC), alginate together with gelatin and chitosan (AGC). Chitosan coating begins with the preparation of chitosan solution according to Chuprom (2010) method. $0.4 \mathrm{~g}$ of chitosan (92\% degree of deacetylation) was dissolved with $90 \mathrm{~mL}$ of distilled water contained $0.4 \mathrm{~mL}$ of acetic acid. The final concentration of chitosan is $0.4 \%$ (w/v). Then, the chitosan solution was adjusted to $\mathrm{pH} 5.7$ with $1 \mathrm{M} \mathrm{NaOH}$ solution. After that, the gel beads (A) and (AG) were soaked into the prepared chitosan solution, shake $100 \mathrm{rpm}$ for 40 minutes, become (AC) and (AGC), respectively. The gel beads were separated from the chitosan solution by filter paper No. 4 , washed the gel beads with $0.1 \%$ peptone solution $(\mathrm{w} / \mathrm{v})$ contained $0.85 \% \mathrm{NaCl}(\mathrm{w} / \mathrm{v})$.

Characteristics of the gel beads. The size of the gel beads (A, AG, AC and AGC) was obtained by vernier caliper. The average size of the gel beads was 
calculated from the mean diameter of 20 gel beads. Morphology of the gel bead (AC contained B. subtilis and AC not contained B. subtilis) was observed by optical microscope (Nikon eclipse E200, Thailand).

\section{Encapsulation of $B$. subtilis in various sizes of the gel beads}

Preparation of the gel beads AC by using 16G, 18G and 20G needles were done. Then, the release of $B$. subtilis from the gel beads and the amount of survival of $B$. subtilis from low $\mathrm{pH}$ was studied.

\section{Encapsulation of $B$. subtilis with chitosan at various times}

Preparation of the gel beads according to method of (AC) was done, but the gel beads were soaked into the prepared chitosan solution, shake $100 \mathrm{rpm}$ for 30,40 , and 50 minutes. Then, the amount of survival of $B$. subtilis from low $\mathrm{pH}$ was studied.

\section{The release of $B$. subtilis from the gel beads}

The release of $B$. subtilis from various gel bead types was studied by put $1 \mathrm{~g}$ of each gel bead type (A, AG, AC, and AGC) into a test tube contained $9 \mathrm{~mL}$ of PBS, pH 7.4. Then, broke the gel beads by vortex in the maximum speed for 10 minutes. After that, centrifuged at 5,000 rpm for 15 minutes, removed the PBS solution, and added $2 \mathrm{~mL}$ of $0.85 \% \mathrm{NaCl}(\mathrm{w} / \mathrm{v})$. Each tube was made a serial ten-fold dilution from $10^{-1}$ to $10^{-6}$. The numbers of release $B$. subtilis were counted by the drop plate method. The Encapsulation efficiency (EE) was calculated based on the formula below, according to Nami et al., 2017.

$$
\mathrm{EE}=\left(\log _{10} N / \log _{10} N_{0}\right) \times 100
$$

Where $N$ is the number viable bacteria (CFU) entrapped by biopolymers, and $N_{0}$ is the number of free viable bacteria before encapsulation.

The release of $B$. subtilis from gel bead at various times was studied according to the method of Haghshenas et al., 2015. Briefly, $5 \mathrm{~g}$ of gel beads were incubated in $50 \mathrm{~mL}$ of $0.1 \mathrm{M} \mathrm{KH}_{2} \mathrm{PO}_{4}, \mathrm{pH} 7.4,100 \mathrm{rpm}$ shaking machine at $37^{\circ} \mathrm{C}$. The samples were taken at different time intervals and the released bacteria were counted by the drop plate method.

\section{Encapsulation efficiency testing for the protection of $\boldsymbol{B}$. subtilis}

The protection of $\boldsymbol{B}$. subtilis from high temperature. One gram of gel beads were put into a test tube containing $2 \mathrm{~mL}$ of PBS, $\mathrm{pH}$ 7.4. Then, incubated in the water bath at 37,60 and $90{ }^{\circ} \mathrm{C}$ for 3 hours. After that, added $7 \mathrm{~mL}$ of PBS, $\mathrm{pH} 7.4$ to each test tube. The gel beads were broke by vortex in the maximum speed for 10 minutes. Then, centrifuged at 5,000 rpm for 15 minutes, removed the PBS solution, and added $2 \mathrm{~mL}$ of $0.85 \% \mathrm{NaCl}(\mathrm{w} / \mathrm{v})$. Each tube was made a 
serial ten-fold dilution from $10^{-1}$ to $10^{-6}$. The numbers of survival $B$. subtilis were counted by the drop plate method. The experiment was done in encapsulated $B$. subtilis compared with free $B$. subtilis (Not encapsulated). The survival rate of $B$. subtilis was calculated based on the formula below:

Survival $(\%)=\frac{\text { Number of } B \text {. subtilis that survived after incubation }(\mathrm{CFU} / \mathrm{ml})}{\text { Number of } B \text {. subtilis that survived after incubated at } 37^{\circ} \mathrm{C}(\mathrm{CFU} / \mathrm{ml})} \times 100$

The protection of $\boldsymbol{B}$. subtilis from low $\mathbf{p H}$. One gram of gel beads were put into a test tube containing $2 \mathrm{~mL}$ of PBS, $\mathrm{pH} \mathrm{2,4}$ and 7.4. Then, incubated in the water bath at $37{ }^{\circ} \mathrm{C}$ for 3 hours. After that, centrifuged at 1,500 rpm for 15 minutes to allow the gel to settle, remove the PBS solution. The gel beads were washed 2 times in $0.85 \% \mathrm{NaCl}(\mathrm{w} / \mathrm{v})$. After that, added $7 \mathrm{~mL}$ of PBS, $\mathrm{pH} 7.4$ to each test tube. The gel beads were broke by vortex in the maximum speed for 10 minutes. Then, centrifuged at 5,000 rpm for 15 minutes, removed PBS solution, and added $2 \mathrm{~mL}$ of $0.85 \% \mathrm{NaCl}(\mathrm{w} / \mathrm{v})$. Each tube was made a serial ten-fold dilution from $10^{-1}$ to $10^{-6}$. The numbers of survival $B$. subtilis were counted by the drop plate method. The experiment was done in encapsulated B. subtilis compared with free B. subtilis (Not encapsulated). The survival rate of $B$. subtilis was calculated based on the formula below:

Survival $(\%)=\frac{\text { Number of } B \text {. subtilis that survived after incubation }(\mathrm{CFU} / \mathrm{mL})}{\text { Number of } B . \text { subtilis that survived after incubated at } \mathrm{pH} 7.4(\mathrm{CFU} / \mathrm{mL})} \times 100$

\section{Statistical analysis}

Every experiment was done in triplicate. The results were shown in the form of Mean $\pm \mathrm{SD}$. Each experiment analyzes the results with one-way analysis of variance (One-way ANOVA) and uses complex comparisons with the Tukey's Multiple Comparison Test at 95\% confidence level $(P<0.05)$.

\section{RESULTS}

\section{Encapsulation of $B$. subtilis with alginate, gelatin, and chitosan}

Characteristics of the gel beads. When encapsulated $B$. subtilis with sodium alginate $(A)$, sodium alginate together with gelatin (AG), sodium alginate together with chitosan (AC), and sodium alginate together with gelatin and chitosan (AGC) using a 18G syringe, found that all forms of gel beads have the same external characteristics that are round and smooth and shiny surface as shown in Figure 1. The gel beads size is $2.31 \pm 0.2 \mathrm{~mm}$ in diameter. In the figure, the food coloring is added in order to see the difference of each type but does not affect any experimental results. 


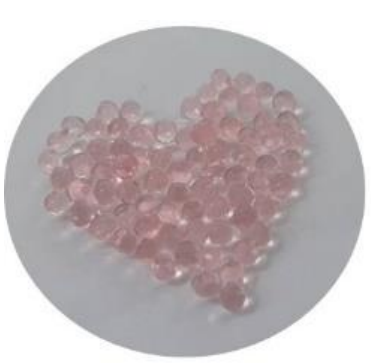

A

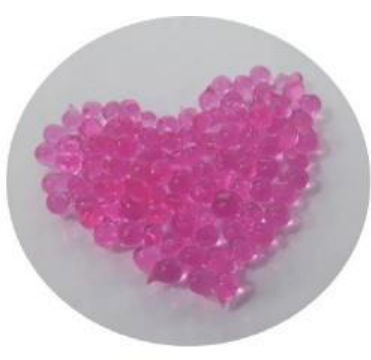

AC

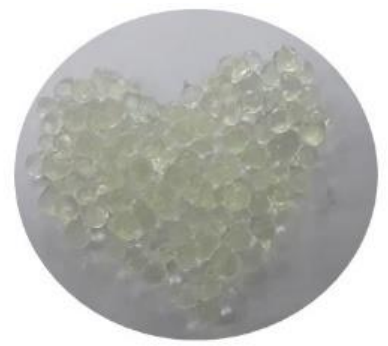

AG

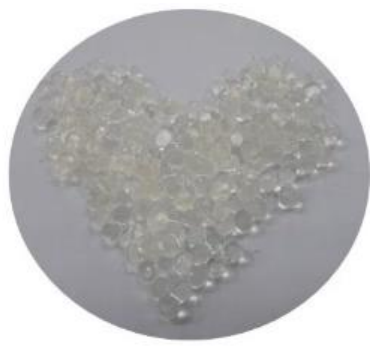

AGC

Figure 1. The appearance of various gel bead types. Each type of gel beads was prepared by using $18 \mathrm{G}$ needle. The food coloring was added to see the difference of each gel type.

AC contained B. subtilis and AC not contained B. subtilis were observed under optical microscope. The surface of the gel beads has a wave-like pattern throughout the gel. In gel beads containing B. subtilis, when observed at magnification of $20 \mathrm{X}$ or above, can see the cells of $B$. subtilis encapsulated in gel beads (the arrow points), as shown in the Figure 2.

(A)
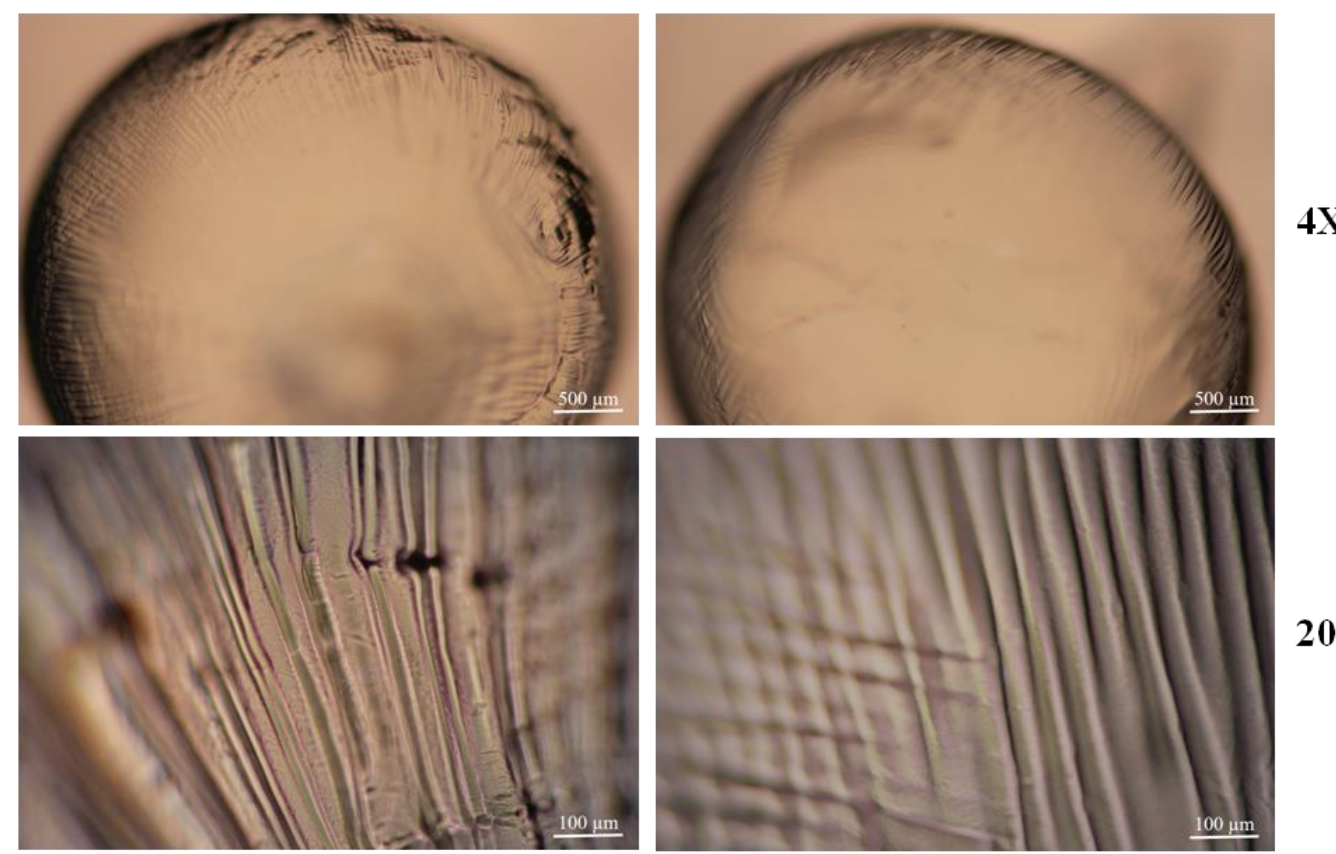

$20 \mathrm{X}$
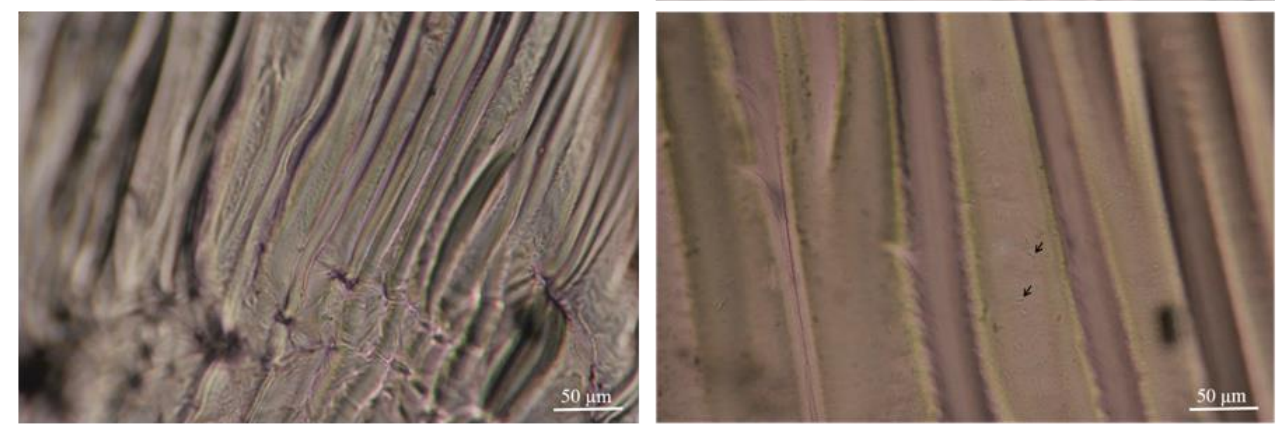

$40 X$

AC

$\mathrm{AC}+B$. subtilis 
(B)

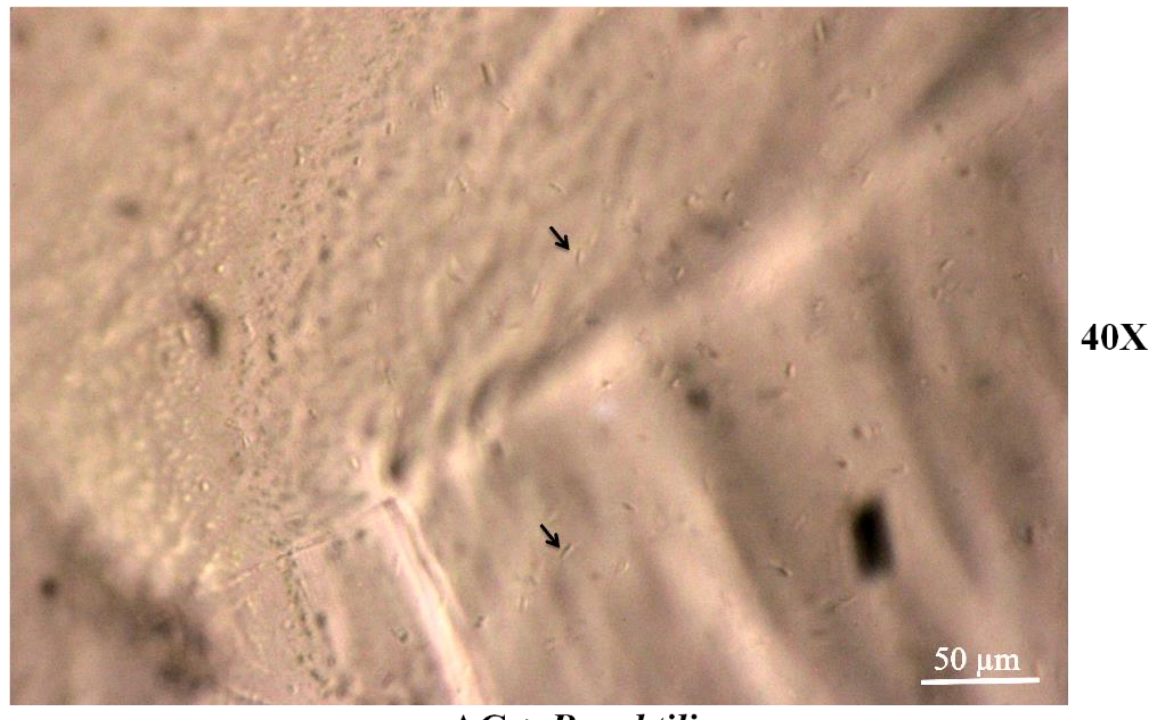

$\mathrm{AC}+$ B. subtilis

Figure 2. (A) The external surface of the gel beads under a optical microscope at various magnifications. (B) B. subtilis cells on the surface of the gel beads.

The release of $B$. subtilis from the gel beads. The amount of release of $B$. subtilis from the gel beads is reduced with statistical significance $(P<0.05)$ when compared with the amount of $B$. subtilis before encapsulation. The group with the highest release of $B$. subtilis is AGC as $1.4 \pm 0.071 \times 10^{5} \mathrm{CFU} / \mathrm{mL}$, followed by $\mathrm{AC}$ as $4 \pm 0.053 \times 10^{4} \mathrm{CFU} / \mathrm{mL}$. Encapsulation efficiency of AGC and AC are 70.09 and 62.68, respectively, as shown in Table 1.

Table 1. The efficiency of $B$. subtilis release from various gel bead types. (Each type of gel beads was prepared by using $18 \mathrm{G}$ needle).

\section{Type of material}

\section{Released B. subtilis} (CFU/mL)

\section{Encapsulation efficiency (EE)}

\begin{tabular}{lll}
\hline A & $9.25 \pm 0.008 \times 10^{3 a}$ & 54.02 \\
AC & $4 \pm 0.053 \times 10^{4 b}$ & 62.68 \\
AG & $7.2 \pm 0.008 \times 10^{3 a}$ & 52.53 \\
AGC & $1.4 \pm 0.071 \times 10^{5 \mathrm{c}}$ & 70.09 \\
\hline
\end{tabular}

Note: Initial B. subtilis concentration (before encapsulated) is $2.2 \pm 0.45 \times 10^{7} \mathrm{CFU} / \mathrm{mL}$. The letters a, b, and c represents a statistically significant difference $(P<0.05)$.

The release of $B$. subtilis from gel bead (AC) at $0,1,2,3,4,5$ and $6 \mathrm{~h}$ was studied. The results show that $B$. subtilis were completely released from the gel 
beads at the $1^{\text {st }} \mathrm{h}$ after shaking the gel in $\mathrm{KH}_{2} \mathrm{PO}_{4}$ solution. And when measuring the amount of $B$. subtilis continuously every $1 \mathrm{~h}$, the amount of $B$. subtilis remained constant until the $6 \mathrm{~h}$, as shown in Figure 3.

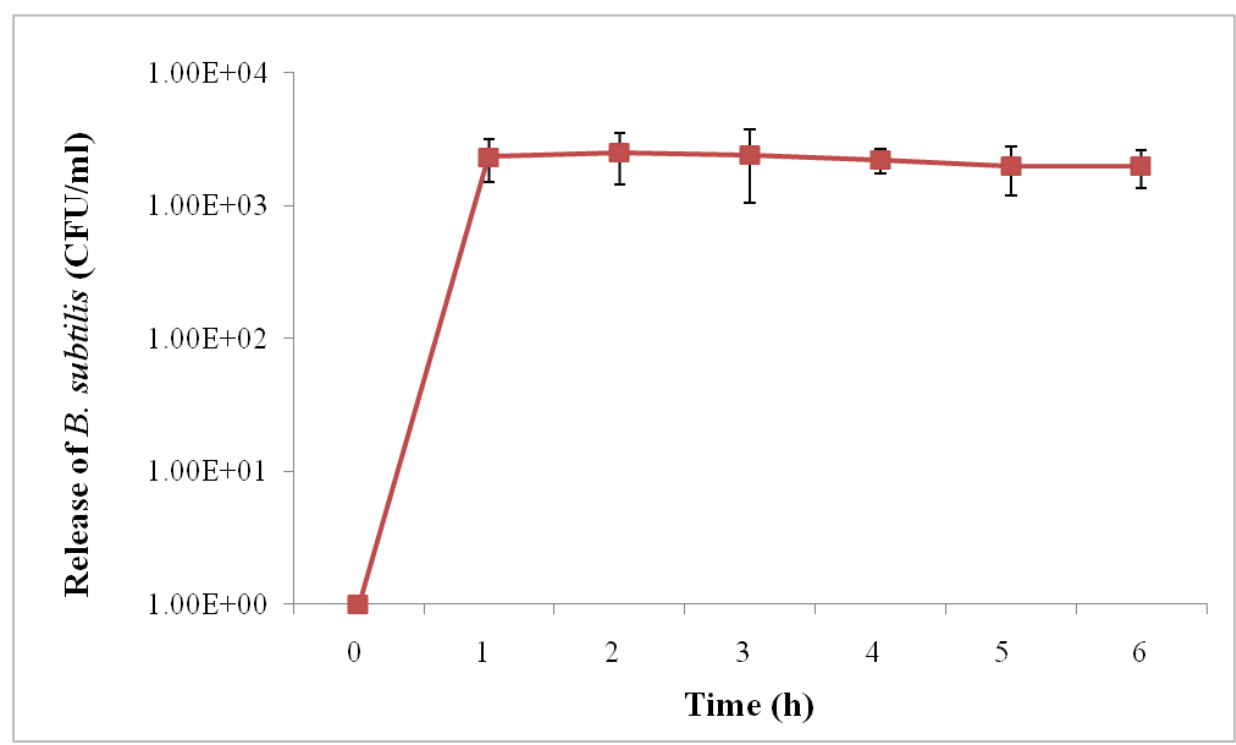

Figure 3. The release of $B$. subtilis from gel bead (AC) at $0,1,2,3,4,5$ and $6 \mathrm{~h}$ after shaking the gel in $\mathrm{KH}_{2} \mathrm{PO}_{4}$ solution.

\section{Encapsulation of $B$. subtilis in various sizes of the gel beads}

Characteristics of the gel beads. $B$. subtilis was encapsulated with AC using various sizes of syringes, including $16 \mathrm{G}, 18 \mathrm{G}$, and $20 \mathrm{G}$. The results showed the round gel beads and the diameter size of the beads are $3.18 \pm 0.27,2.31 \pm 0.20$ and $1.5 \pm 0.18 \mathrm{~mm}$, respectively. From Chuprom's (2010) experiment, $L$. acidophilus TISTR 1034 was encapsulated with $2 \%$ sodium alginate using needle size $18 \mathrm{G}, 22 \mathrm{G}, 24 \mathrm{G}$, and $27 \mathrm{G}$. The results showed that the gel bead sizes are 2.4 , $2.1,2.08$, and $1.8 \mathrm{~mm}$, respectively.

The protection of $B$. subtilis from low $\mathbf{p H}$. Base on the survival of $B$. subtilis encapsulated with AC by using the needle sizes at 16G, 18G, and $20 \mathrm{G}$ in $\mathrm{pH} \mathrm{4}$, the results were shown in Figure 4. It was found that the gel beads encapsulated using the needle size at $18 \mathrm{G}$ has a significantly higher number of surviving $B$. subtilis $(P<0.05)$, that is $6.3 \times 10^{4} \mathrm{CFU} / \mathrm{mL}$, compared with the gel beads encapsulated using the needle sizes at $16 \mathrm{G}$ and $20 \mathrm{G}$, that are $1.2 \times 10^{4}$ and $1.3 \times 10^{4} \mathrm{CFU} / \mathrm{mL}$, respectively. The gel beads encapsulated using the needle sizes at $16 \mathrm{G}$ and $20 \mathrm{G}$ was not significantly different $(P>0.05)$. Accordingly, in $\mathrm{pH} 7.4$, the gel beads encapsulated using the needle size at $18 \mathrm{G}$ has a significantly higher number of surviving B. subtilis $(P<0.05)$, that is $2.6 \times 10^{4} \mathrm{CFU} / \mathrm{mL}$, compared with the gel beads encapsulated using the needle sizes at $16 \mathrm{G}$ and $20 \mathrm{G}$, that are $1.0 \times 10^{3}$ and $4.4 \times 10^{3} \mathrm{CFU} / \mathrm{mL}$, respectively. Therefore, the needle size at $18 \mathrm{G}$ produced effective gel beads that protect $B$. subtilis from low $\mathrm{pH}$. 

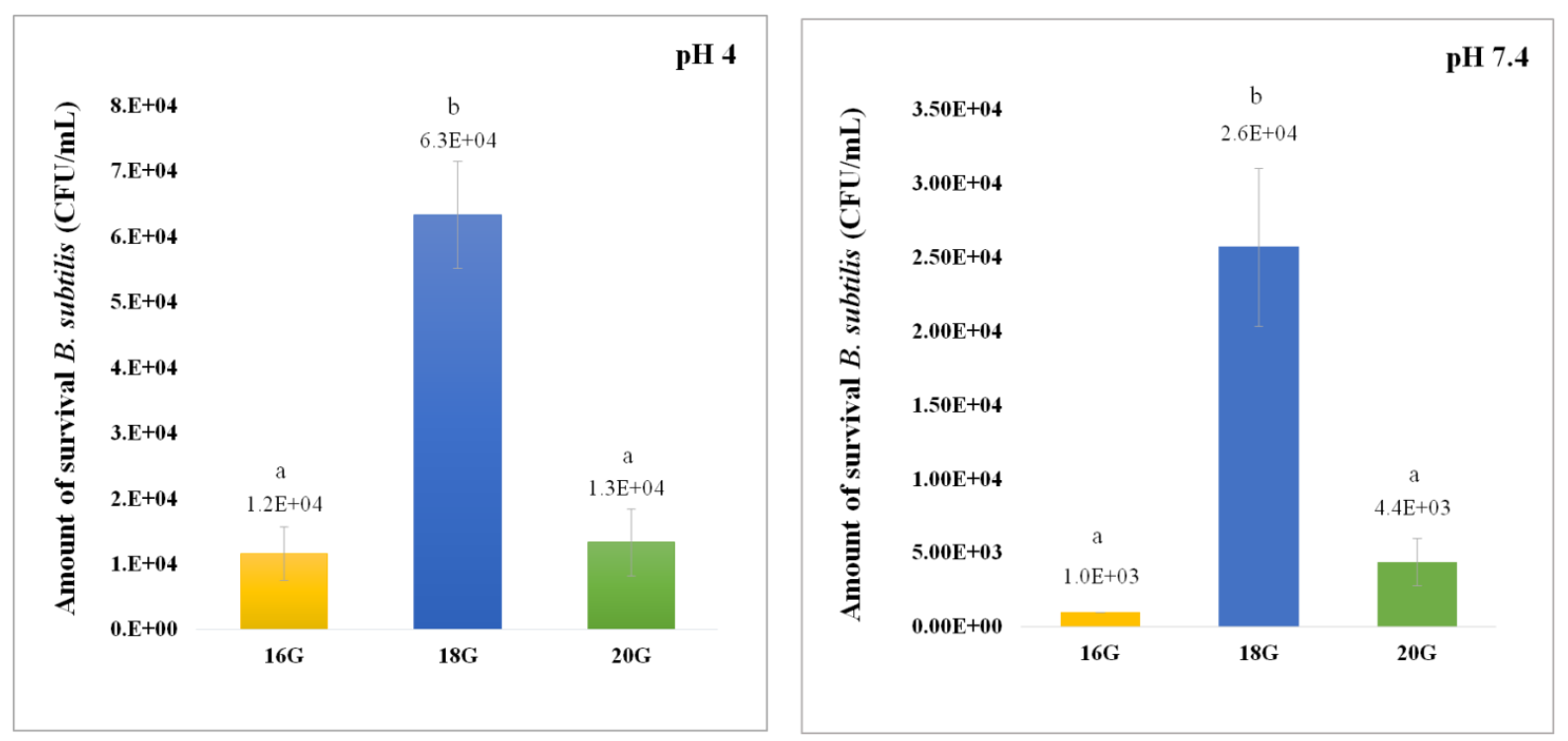

Figure 4. Amount of B. subtilis that survived after incubation at $\mathrm{pH} 4$ (left) and $\mathrm{pH} 7.4$ (right) for 3 hours. Gel beads (AC) are prepared using various sizes of needles. The letter $(a, b)$ represents a statistically significant difference $(P<0.05)$.
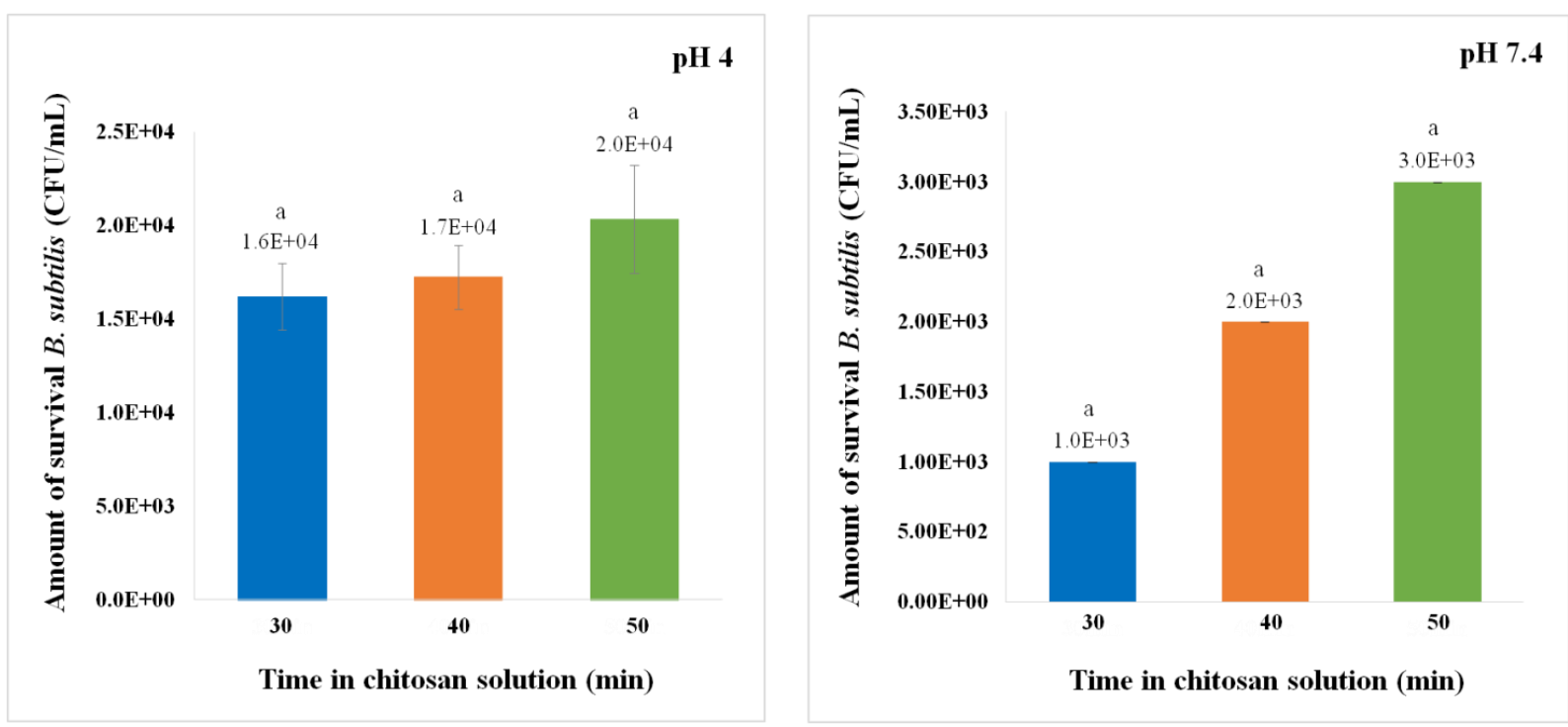

Figure 5. Amount of B. subtilis that survived after incubation at $\mathrm{pH} 4$ (left) and $\mathrm{pH} 7.4$ (right) for 3 hours. Gel beads (AC) are prepared using 18G needle and soaked in chitosan solution for 30, 40 and 50 minutes. The letter (a) represents a statistically significant difference $(P<0.05)$.

\section{Encapsulation of $B$. subtilis with chitosan at various times}

B. subtilis was encapsulated with AC by using needle size $18 \mathrm{G}$. Then, the gel beads were soaked into the chitosan solution for 30, 40, and 50 minutes and the survival of $B$. subtilis in $\mathrm{pH} 4$ was studied. The amount of the survival of encapsulated B. subtilis that soaked in chitosan solution for 30,40 , and $50 \mathrm{~min}$ 
are $1.6 \times 10^{4}, 1.7 \times 10^{4}$, and $2.0 \times 10^{4} \mathrm{CFU} / \mathrm{mL}$, respectively. But when applied to statistical testing, it was found that there was no significant difference $(P>0.05)$ as showed in Figure 5. Correspondingly, in $\mathrm{pH} 7.4$, the amount of the survival of encapsulated B. subtilis that soaked in chitosan solution for 30,40 , and $50 \mathrm{~min}$ are $1.0 \times 10^{3}, 2.0 \times 10^{3}$, and $3.0 \times 10^{3} \mathrm{CFU} / \mathrm{mL}$, respectively.

\section{Encapsulation efficiency testing for the protection of $B$. subtilis}

The protection of $B$. subtilis from high temperature. From the experiment of the survival of encapsulated $B$. subtilis at $60{ }^{\circ} \mathrm{C}$, the percentage survival of $B$. subtilis encapsulated with AGC and non-encapsulated $B$. subtilis (BS) is not significantly different $(P>0.05)$, but the percentage survival of $B$. subtilis encapsulated with AC increases when compared to BS and AGC as statistically significant $(P<0.05)$, as shown in Figure 5 . The average percentage survival of BS, AC and AGC are $4.83 \%, 48.38 \%$, and $6.49 \%$, respectively. From the experiment of the survival of encapsulated B. subtilis at $90{ }^{\circ} \mathrm{C}, \mathrm{B}$. subtilis encapsulated with $\mathrm{AC}$ has the highest percentage survival and significantly different when compared with BS and AGC $(P<0.05)$. Followed by, AGC which increased percentage survival when compared to BS with statistically significant $(P<0.05)$ as also shown in Figure 6. The average percentage survival of BS, AC and AGC are $9.67 \%, 40.32 \%$ and $27.59 \%$, respectively. According to the study of Praepanitchai et al. (2019), L. plantarum was encapsulated with hybrid alginate-soy protein and then the survival of the encapsulated L. plantarum was evaluated by treating the beads at $30,50,63$, and $72{ }^{\circ} \mathrm{C}$. The encapsulated $L$. plantarum was found still alive after incubated at $72{ }^{\circ} \mathrm{C}$ for $90 \mathrm{~s}$, while most free cells do not survive at temperatures above $50{ }^{\circ} \mathrm{C}$.

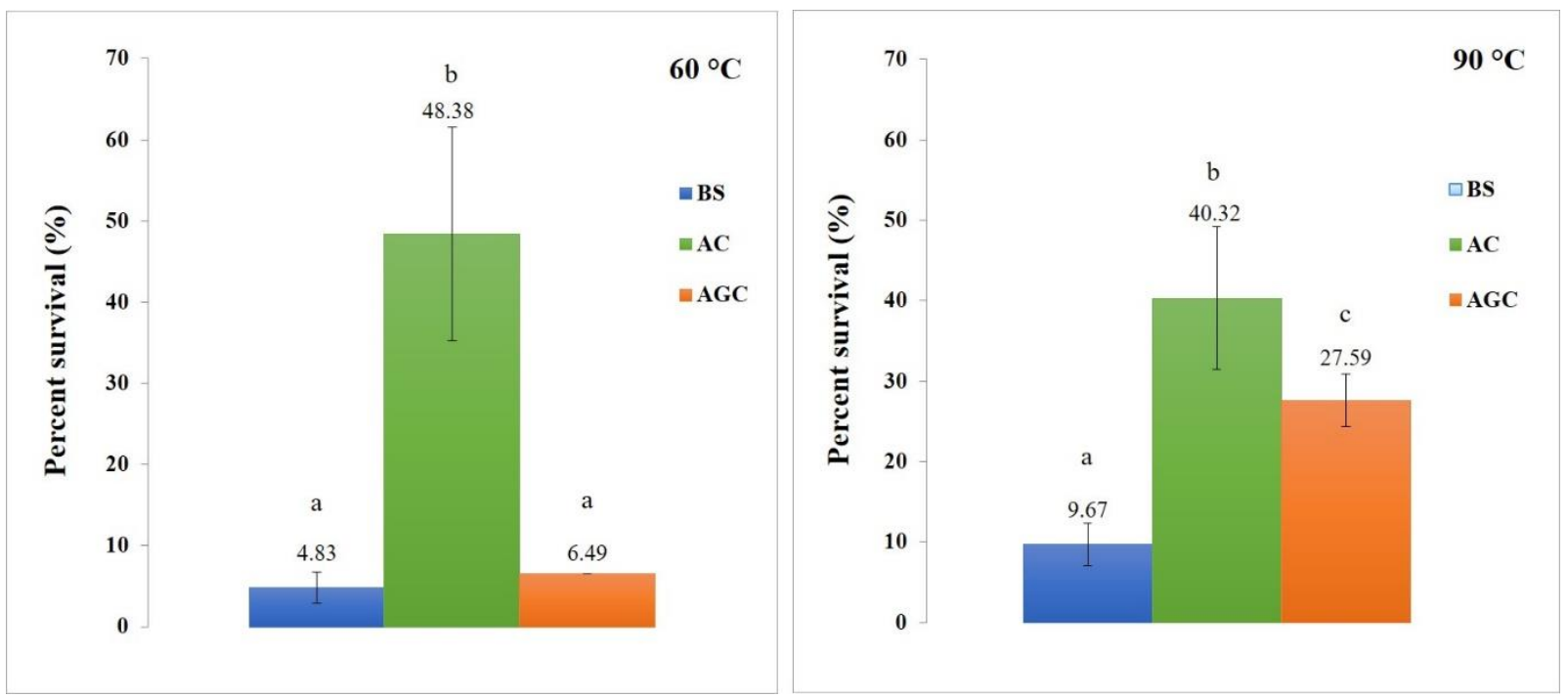

Figure 6. Percent survival of $B$. subtilis encapsulated with $\mathrm{AC}$ and AGC after incubation at $60^{\circ} \mathrm{C}$ (left) and $90^{\circ} \mathrm{C}$ (right) for 3 hours, compared with non-encapsulated $B$. subtilis. The letter $(\mathrm{a}, \mathrm{b}, \mathrm{c})$ represents a statistically significant difference $(P<0.05)$. 
The protection of $B$. subtilis from low $\mathbf{p H}$. From the survival test of encapsulated $B$. subtilis at $\mathrm{pH} 4$, the percentage survival of $B$. subtilis encapsulated with AC and AGC were not significantly different $(P>0.05)$, but increased significantly compared to BS $(P<0.05)$ as showed in Fig. 5. The average percentage survival of BS, AC and AGC are 1.04\%, 98.03\% and 90.9\%, respectively. From the survival test of encapsulated B. subtilis at $\mathrm{pH} 2$ corresponding to $\mathrm{pH} 4$, but the survival is less than $\mathrm{pH} 4$. The percentage survival of $B$. subtilis encapsulated with AC and AGC were not significantly different $(P>0.05)$, but increased significantly compared to BS $(P<0.05)$ as also showed in Figure 7. The average percentage survival of BS, AC and AGC are $0.15 \%$, $45.15 \%$, and $51.02 \%$, respectively.

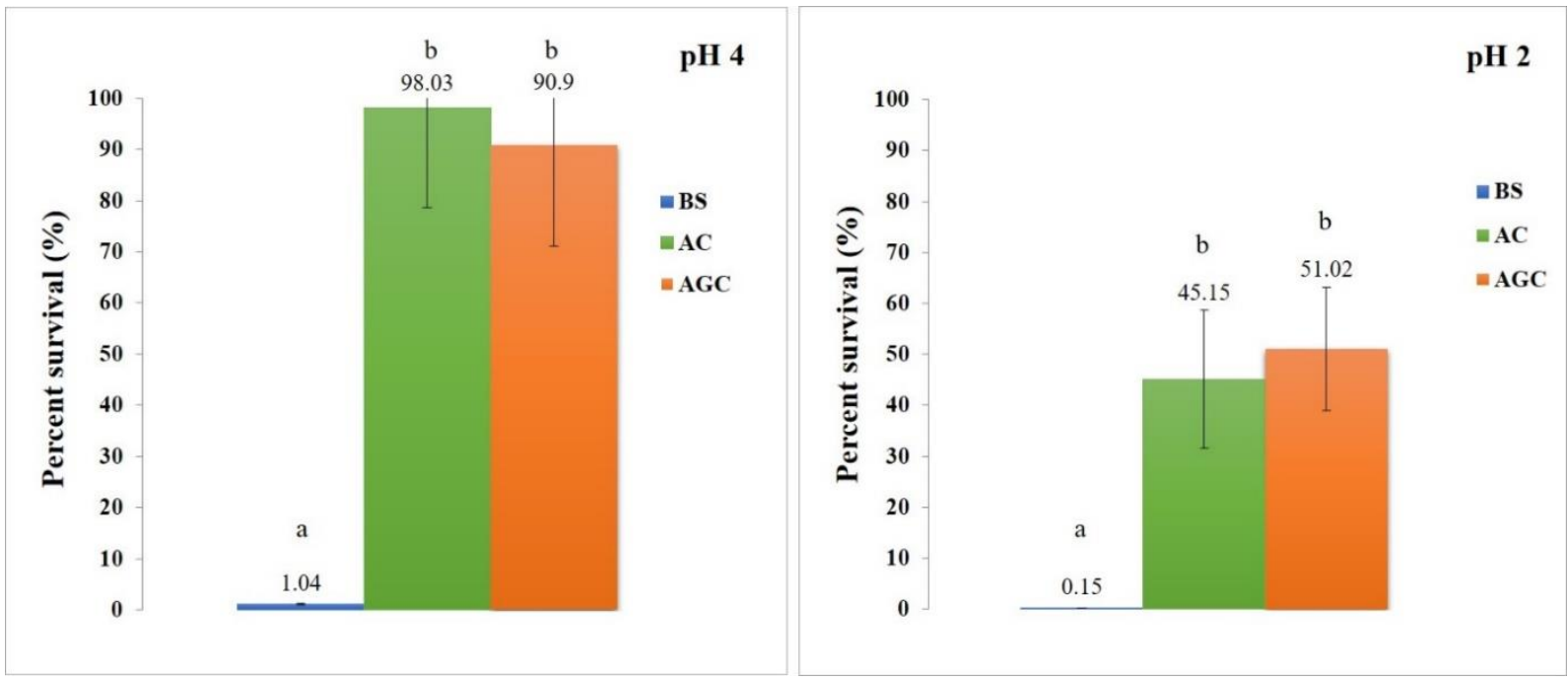

Figure 7. Percent survival of B. subtilis encapsulated with AC and AGC after incubation at $\mathrm{pH} 4$ (left) and $\mathrm{pH} 2$ (right) for 3 hours, compared with non-encapsulated $B$. subtilis. The letter $(\mathrm{a}, \mathrm{b})$ represents a statistically significant difference $(P<0.05)$.

\section{DISCUSSION}

B. subtilis (TISTR 2057) was tested for $\mathrm{pH}$ resistance in an intestinal tract. It showed potential to be antimicrobial against broiler-chicken pathogen and to produce digestive enzyme for growth promotion (Sriyam et al., 2011). In addition to Bacillus spp., there are other probiotics that are commonly used in aquatic animals, including Enterococcus spp., Lactobacillus spp., Lactococcus sp., Micrococcus, and etc. (Abd El-Rhman et al., 2009; Safari et al., 2016; Yu et al., 2017; Feng et al., 2019; Yang et al., 2019). However, Bacillus spp. have been proven to have better probiotic properties due to their ability to produce antimicrobial agents many types of microorganisms, non-pathogenic and nontoxic. With the ability to create spores, they have two advantages in terms of 
survival (resistant to heat and longer shelf life) in various environments compared to other probiotics.

This study reported that the alginate, gelatin, and chitosan can protect the cells to survive in severe conditions. This is new and significant because previously, there are no any reports of $B$. subtilis encapsulation in these materials. Young et al., 2006 encapsulated of a B. subtilis CC-pg104 with alginate by enriching the bead microenvironment with humic acid. High viability of the encapsulated bacteria was observed with minimum cell loss upon storage for 5 months. Steady and constant cell release from the bead was observed for 1 week at different $\mathrm{pH}$. Ma et al., 2015 developed a microencapsulation procedure of B. subtilis B99-2 using maltodextrin and gum arabic as wall materials. They found that Maltodextrin is an efficient wall material, the mean survival rate of B. subtilis was more than $90 \%$, when spray drying was performed at $145^{\circ} \mathrm{C}$ and B. subtilis microcapsule survival rate was $87.53 \%$ after 540 days of storage. Barlow et al., 2017 encapsulated B. subtilis in a semi-permeable membrane composed of mPEG-PDLLA. This polymer membrane was sufficiently permeable to permit exponential bacterial growth, metabolite-induced gene expression, and rapid biofilm growth.

Alginate is a natural polymer used in the food and drug industry because of its mild gel formation, biological compatibility, and biodegradability. There is a growing interest in using alginate in a variety of scientific fields such as oral vaccination, development of drug release systems and microencapsulation of cells for continuous control and delivery of treatment products (Amirheidari et al., 2016). Chitosan is an alternative for microcapsule coating. It is also the most positively charged polysaccharide and can be obtained by alkaline removal of chitin. Due to its low toxicity, good biocompatibility and controlled biodegradability, it is used as an active ingredient in encapsulation (Chen et al., 2007, Chen et al., 2009). It is also reported that the substrate is suitable for bio-polymers due to the structure similar to glycosaminoglycans found in tissues. When using alginate and chitosan to encapsulate, alginate-chitosan capsules (AC) occurs due to the reaction between electrostatic charge and both polysaccharides with opposite charge. Live microorganisms, cells, DNA, proteins, and enzymes in AC have been studied extensively (Chen et al., 2009).

The size of the gel beads is determined by many factors including the type of bacteria needle size, sodium alginate solution concentration and distance between syringe and calcium chloride solution. The size of the gel beads produced by the extrusion method will be between $500 \mu \mathrm{m}$ to $3 \mathrm{~mm}$ in diameter (Burey et al., 2008). In this study, the diameter size of the beads prepared by $16 \mathrm{G}$, 
$18 \mathrm{G}$, and $20 \mathrm{G}$ needles are $3.18 \pm 0.27,2.31 \pm 0.20$ and $1.5 \pm 0.18 \mathrm{~mm}$, respectively. Chandramoulia et al. (2004) studied the survival of the L. acidophilus which is encapsulated by $1.5 \%$ sodium alginate, by preparing various sizes of gel bead. It was found that the survival of the encapsulated bacteria increased as the size of the gel increased. By reasoning that the large gel beads will have a surface area that will be exposed to various harmful conditions less than small gel beads. While Totosaus et al., 2013 indicated that the gel beads that have a less exposed surface area are stronger, more flexible and less viscous. Therefore, the larger gel beads are more likely to break or leak easily than small gel beads. In addition, Lee and Heo, 2000 reported that the large gel beads may cause roughness of the texture in fresh microbial supplements. Therefore, the gel bead size should be in the appropriate range, not too large or too small.

From the experiment found that the amount of release of B. subtilis from the gel beads is reduced with statistical significance $(P<0.05)$ when compared with the amount of $B$. subtilis before encapsulation. The amount of $B$. subtilis disappeared, it is possible that some of $B$. subtilis are combined together with the gel and some are still trapped inside the gel. Indicated by, after vortex the gel beads in the maximum speed for 10 minutes, it was found that the gel beads that were encapsulated with chitosan were easier broken than the no chitosan gel beads. In this experiment, AC and AGC are easier broken than A and AG, resulting in a greater amount of bacteria released. In living animals, if the gel beads are sticky and difficult to break when in the digestive tract of animals, the amount of bacteria released is low. This may result in an insufficient amount of probiotics for function. Therefore, the researcher has chosen two groups of gel beads that have the good release of $B$. subtilis that are AC and AGC for further experiments. Haghshenas et al., 2015 reported that Lactobacillus plantarum $15 \mathrm{HN}$ using alginate-psyllium-fenugreek polymeric blends has release occurred after $2 \mathrm{~h}$ in colonic condition and sustained until the $12^{\text {th }} \mathrm{h}$ incubation period. While in this study, B. subtilis release occurred at $1^{\text {st }} \mathrm{h}$ and remained constant until the $6^{\text {th }} \mathrm{h}$ incubation period.

When poured the sodium alginate solution containing cell suspension into the calcium solution, the bound ions will interact with other GG blocks to create complexities that lead to gel formation, resulting in protecting cells that are released in the intestine tract (Prakash and Jones, 2005). Encapsulation in 2\% alginate containing $2 \% \mathrm{Hi}$-maize resistant starch bead improved the survival of L. plantarum CM53 in simulated GIT significantly $(P<0.05)$. L. plantarum and free cells survival after incubated in stomach gastric juice (SGJ) for $3 \mathrm{~h}$ was $89.55 \%$ and $69.82 \%$, respectively (Ayama et al., 2014). In this study, the encapsulation efficiency quite low (only 62.68) but the survival of B. subtilis is high as the average percentage survivals of $\mathrm{AC}$ and $\mathrm{AGC}$ at $\mathrm{pH} 4$ are $98.03 \%$ and $90.9 \%$, respectively. The previous study indicated that the level of bacteria survival was increased when co-encapsulate alginate with other material. Coating of gelatin microspheres with alginate provided significant protection 
for Bifidobacterium adolescentis $15703 \mathrm{~T}$ from the harsh acidic conditions of simulated gastric fluid (SGF) (Annan et al., 2008). Many kinds of research indicated that the alginate-chitosan encapsulation provided significant protection of probiotics bacteria in SGF with statistical significance compared to free cells (Chavarri et al., 2010; Li et al., 2011).

\section{CONCLUSION}

The gel beads of A, AG, AC, and AGC have the same external characteristics that are a round and smooth surface. The gel beads using $18 \mathrm{G}$ needle has the highest amount of $B$. subtilis release and made effective gel beads that protect $B$. subtilis from low $\mathrm{pH}$. Optimal duration of soaking the gel beads in chitosan is $30 \mathrm{~min}$. B. subtilis encapsulated with AC has the highest percentage survival in high temperature. B. subtilis encapsulated with AC and AGC provides equally high percentage survival in low $\mathrm{pH}$. This experiment will be the basis for the use of these encapsulated gel beads in animals. To supplement beneficial probiotic bacteria that able to withstand critical conditions in the digestive tract of animals, it may be added to animal feed or allow animals to eat in other methods.

\section{ACKNOWLEDGEMENTS}

The authors would like to thank the Rajamangala University of Technology Srivijaya (RUTS) for research funding. And thank you, Faculty of Veterinary Science, for kindly providing research facilities. Finally, the authors would like to express their gratitude to all the students who assisted with this research.

\section{REFERENCES}

Abd El-Rhman, A.M., Khattab Y.A., and Shalaby, A.M. 2009. Micrococcus luteus and Pseudomonasspecies as probiotics for promoting the growth performance and health of Nile tilapia, Oreochromis niloticus. Fish \& Shellfish Immunology. 27(2): 175-180. https://10.1016/j.fsi.2009.03.020

AlGburi, A., Volski, A., Cugini, C., Walsh, E., Chistyakov, V., Mazanko, M., Bren, A., Dicks, L., and Chikindas, M. 2016. Safety properties and probiotic potential of Bacillus subtilis KATMIRA1933 and Bacillus amyloliquefaciens B-1895. Advances in Microbiology. 6: 432-452. https://doi.org/10.4236/aim.2016.66043

Amirheidari, B., Badinloo, S., Ohadi, M., and Noudeh, G.D. 2016. Bioencapsulation of biosurfactant-producing Bacillus subtilis (PTCC 1023) in alginate beads. Jundishapur Journal of Natural Pharmaceutical Products. 11(4):e33935. https://doi.org/10.17795/jjnpp-33935. 
Annan, N.T., Borza, A.D., and Hansen, L.T. 2008. Encapsulation in alginatecoated gelatin microspheres improves survival of the probiotic Bifidobacterium adolescentis 15703T during exposure to simulated gastro-intestinal conditions. Food Research International. 41(2): 184-193. https://doi.org/10.1016/j.foodres.2007.11.001

Ayama, H., Sumpavapol, P., and Chanthachum, S. 2014. Effect of encapsulation of selected probiotic cell on survival in simulated gastrointestinal tract condition. Songklanakarin Journal of Science and Technology. 36(3): 291299.

Bansode, S.S., Banarjee, S.K., Gaikwad, D.D., Jadhav, S.L., and Thorat, R.M. 2010. Microencapsulation: A review. International Journal of Pharmaceutical Sciences Review and Research. 1(2): 38-43.

Barlow, J., Gozzi, K., Kelley, C.P., Geilich, B.M., Webster T.J., Chai, Y., Sridhar, S., and van de Ven, A.L. 2017. High throughput microencapsulation of Bacillus subtilis in semi-permeable biodegradable polymersomes for selenium remediation. Applied Microbiology and Biotechnology. 101(1): 455-464. https://doi.org/10.1007/s00253-01678967

Burey, P., Bhandari, B.R., Howes, T., and Gidley, M.J. 2008. Hydrocolloid gel particles, formation, characterization, and application. Critical Reviews in Food Science and Nutrition. 48: 361-377. https://doi.org/10.1080/10408390 701347801

Chandramoulia, V., Kailasapathya, K., Peirisb, P., and Jones, M. 2004. An improved method of microencapsulation and its evaluation to protect Lactobacillus spp. in simulated gastric condition. Journal of Microbiological Methods. 56: 27-35. https://doi.org/10.1016/j.mimet.2003.09.002

Chavarri, M., Maranon, I., Ares, R., Ibanez, F.C., Marzo, F., and Villaran Mdel, C. 2010. Microencapsulation of a probiotic and prebiotic in alginate-chitosan capsules improves survival in simulated gastro-intestinal conditions. International Journal of Food Microbiology. 142: 185-189. https://doi.org/10.1016/j.ijfoodmicro.2010.06.022

Chen, H., Ouyang, W., Jones, M., Metz, T., Martoni, C., Haque, T., Cohen, R., Lawuyi, B., and Prakash, S. 2007. Preparation and characterization of novel polymeric microcapsules for live cell encapsulation and therapy. Cell Biochemistry and Biophysics. 47: 159-167.

Chen, H., Ouyang, W., Martoni, C., and Prakash, S. 2009. Genipin cross-linked polymeric alginate chitosan microcapsules for oral delivery: in-vitro analysis. International Journal of Polymer Science. 2009: 1681-9422. https://doi.org/10.1155/2009/617184.

Chuprom, J. 2010. Co-encapsulation of probiotics with prebiotics and evaluation of survival under in vitro acidic and bile salt conditions (unpublished master's thesis), Prince of Songkla University, SongKhla, Thailand. 
Feng, J., Chang, X., Zhang, Y., Yan, X., Zhang, J., and Nie, G. 2019. Effects of Lactococcus lactis from Cyprinus carpio L. as probiotics on growth performance, innate immune response and disease resistance against Aeromonas hydrophila. Fish and Shellfish Immunology. 93: 73-81. https://doi.org/10.1016/j.fsi.2019.07.028

Gandomi, H., Abbaszadeh, S., Misaghi, A., Bokaie, S., and Noori, N. 2016. Effect of chitosan-alginate encapsulation with inulin on survival of Lactobacillus rhamnosus $G G$ during apple juice storage and under simulated gastrointestinal conditions. LWT - Food Science and Technology. 69: 365371. https://doi.org/10.1016/j.lwt.2016.01.064

Haghshenas, B., Abdullah, N., Nami, Y., Radiah, D., Rosli, R., and Yari Khosroushahi, A. 2015. Microencapsulation of probiotic bacteria Lactobacillus plantarum $15 \mathrm{HN}$ using alginate-psyllium-fenugreek polymeric blends. Journal of Applied Microbiology. 118(4): 1048-1057. https://doi.org/10.1111/jam.12762

Hong, H.A., Duc le, H., and Cutting, S.M. 2005. The use of bacterial spore formers as probiotics. FEMS Microbiology Reviews. 29(4): 813-835. https://doi.org/10.1016/j.femsre.2004.12.001

Kesarcodi-Watson, A., Kaspar, H., Lategan, M.J., and Gibson, L. 2008. Probiotics in aquaculture: the need, principles and mechanisms of action and screening processes. Aquaculture. 274(1): 1-14. https://doi.org/10.1016/ j.aquaculture.2007.11.019

Lee, K.Y., and Heo, T.R. 2000. Survival of Bifidobacterium longum immobilized in calcium alginate beads in simulated gastric juices and bile salt solution. Applied and Environmental Microbiology. 66(2): 869-873. https://doi.org/ 10.1128/aem.66.2.869-873.2000

Li, X.Y., Chen, X.G., Sun, Z.W., Park, H.J., and Cha, D.S. 2011. Preparation of alginate/chitosan/carboxymethyl chitosan complex microcapsules and application in Lactobacillus casei ATCC 393. Carbohydrate Polymers. 83(4): 1479-1485. https://doi.org/10.1016/j.carbpol.2010.09.053

Ma, X., Wang, X., Cheng, J., Nie, X., Yu, X., Zhao, Y., and Wang W. 2015. Microencapsulation of Bacillus subtilis B99-2 and its biocontrol efficiency against Rhizoctonia solani in tomato. Biological Control. 90: 34-41. https://doi.org/10.1016/j.biocontrol.2015.05.013

Makled, S.O., Hamdan, A.M., El-Sayed, A.M., and Hafez, E.E. 2017. Evaluation of marine psychrophile, Psychrobacter namhaensis SO89, as a probiotic in Nile tilapia (Oreochromis niloticus) diets. Fish \& Shellfish Immunology. 61: 194-200. https://doi.org/10.1016/j.fsi.2017.01.001

Mathews, S. 2017. Microencapsulation of probiotics by calcium alginate and gelatin and evaluation of its survival in simulated human gastro-intestinal condition. International Journal of Current Microbiology and Applied. 6(4): 2080-2087. https://doi.org/10.20546/ijcmas.2017.604.245 
Nami, Y., Haghshenas, B., and Yari Khosroushahi, A. 2017. Effect of psyllium and gum Arabic biopolymers on the survival rate and storage stability in yogurt of Enterococcus durans IW 3 encapsulated in alginate. Food science \& nutrition. 5(3), 554-563. https://doi.org/10.1002/fsn3.430

Park, Y., Moniruzzaman, M., Lee, S., Hong, J., Won, S., Lee, J.M., Yun, H., Kim, K.W., Ko, D., and Bai, S.C. 2016. Comparison of the effects of dietary single and multi-probiotics on growth, non-specific immune responses and disease resistance in starry flounder, Platichthys stellatus. Fish \& Shellfish Immunology. 59: 351-357. https://doi.org/10.1016/j.fsi.2016.11.006

Praepanitchai, O.A., Noomhorm, A., and Anal, A.K. 2019. Survival and behavior of encapsulated probiotics (Lactobacillus plantarum) in calcium-alginatesoy protein isolate-based hydrogel beads in different processing conditions ( $\mathrm{pH}$ and temperature) and in pasteurized mango juice, BioMed Research International. 2019: https://doi.org/10.1155/2019/9768152.

Prakash, S., and Jones, M.L. 2005. Artificial cell therapy: new strategies for the therapeutic delivery of live bacteria. Journal of Biomedicine and Biotechnology. 1: 44-56. https://doi.org/10.1155/S1110724304401065

Pinpimai, K., Rodkhum, C., Chansue, N., Katagiri, T., Maita, M., and Pirarat, N. 2015 . The study on the candidate probiotic properties of encapsulated yeast, Saccharomyces cerevisiae JCM7255, in Nile Tilapia (Oreochromis niloticus). Research in Veterinary Science. 102: 103-111. https://doi.org/ 10.1016/j.rvsc.2015.07.021

Safari, R., Adel, M., Lazado, C.C., Caipang, C.M., and Dadar, M. 2016. Hostderived probiotics Enterococcus casseliflavus improves resistance against Streptococcus iniae infection in rainbow trout (Oncorhynchus mykiss) via immunomodulation. Fish \& Shellfish Immunology. 52: 198-205. https://doi.org/10.1016/j.fsi.2016.03.020

Sriyam, K., Domrongpokkaphan, V. and Pewnim, T. 2011. Strain selection of probiotic Bacillus spp. against broiler chicken pathogen. Proceedings of the $23^{\text {rd }}$ Annual Meeting of the Thai Society for Biotechnology "Systems Biotechnology: Quality \& Success"”. p.250-251.

Standen, B.T., Peggs, D.L., Rawling, M.D., Foey, A., Davies, S.J., Santos, G.A., and Merrifield, D.L. 2016. Dietary administration of a commercial mixedspecies probiotic improves growth performance and modulates the intestinal immunity of tilapia, Oreochromis niloticus. Fish \& Shellfish Immunology. 49: 427-435. https://doi.org/10.1016/j.fsi.2015.11.037

Trabelsi, I., Ayadi, D., Bejar, W., Bejar, S., Chouayekh, H., and Ben Salah,R. 2014. Effects of Lactobacillus plantarum immobilization in alginate coated with chitosan and gelatin on antibacterial activity. International Journal of Biological Macromolecules. 64: 84-89. https://doi.org/10.1016/j.ijbiomac. 2013.11.031 
Totosaus, A., Ariza-Ortega, T.J., and Pérez-Chabela, M.L. 2013. Lactic acid bacteria microencapsulation in sodium alginate and other gelling hydrocolloids mixtures. Journal of Food and Nutrition Research. 52(2): 107120.

Wu, Y., and Zhang, G. 2018. Synbiotic encapsulation of probiotic Latobacillus plantarum by alginate -arabinoxylan composite microspheres. LWT-Food Science and Techology. 93: 135-141.

Yang, Q., Lü, Y., Zhang, M., Gong, Y., Li, Z., TuanTran, N., He, Y., Zhu, C., Lu, Y., Zhang, Y., et al. 2019. Lactic acid bacteria, Enterococcus faecalisY17 and Pediococcus pentosaceus G11, improved growth performance, and immunity of mud crab (Scylla paramamosain). Fish \& Shellfish Immunology. 93: 135-143. https://doi.org/10.1016/j.fsi.2019.07. 050

Young, C.C., Rekha, P.D., Lai, W.A., and Arun, A.B. 2006. Encapsulation of plant growth-promoting bacteria in alginate beads enriched with humic acid. Biotechnology and Bioengineering. 95(1): 76-83. https://doi.org/10.1002/ bit.20957

Yu, L., Zhai, Q., Zhu, J., Zhang, C., Li, T., Liu, X., Zhao, J., Zhang, H., Tian, F., and Chen, W. 2017. Dietary Lactobacillus plantarum supplementation enhances growth performance and alleviates aluminum toxicity in tilapia. Ecotoxicology and Environmental Safety. 143: 307-314. https://doi.org/ 10.1016/j.ecoenv.2017.05.023 